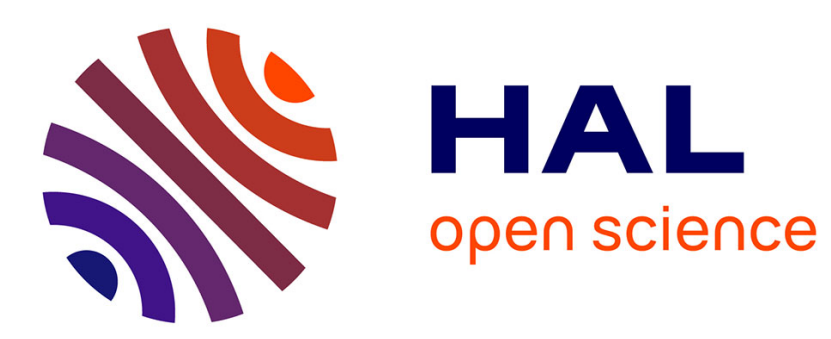

\title{
High temperature mechanical properties and intergranular structure of sialons
}

\author{
Alain Thorel, J.Y. Laval, Daniel Broussaud
}

\section{To cite this version:}

Alain Thorel, J.Y. Laval, Daniel Broussaud. High temperature mechanical properties and intergranular structure of sialons. Journal de Physique Colloques, 1986, 47 (C1), pp.C1-353-C1-357. 10.1051/jphyscol:1986152 . jpa-00225582

\section{HAL Id: jpa-00225582 https://hal.science/jpa-00225582}

Submitted on 1 Jan 1986

HAL is a multi-disciplinary open access archive for the deposit and dissemination of scientific research documents, whether they are published or not. The documents may come from teaching and research institutions in France or abroad, or from public or private research centers.
L'archive ouverte pluridisciplinaire HAL, est destinée au dépôt et à la diffusion de documents scientifiques de niveau recherche, publiés ou non, émanant des établissements d'enseignement et de recherche français ou étrangers, des laboratoires publics ou privés. 
JOURNAL DE PHYSIQUE

Colloque $\mathrm{C1}$, supplément au $\mathrm{n}^{\circ} 2$, Tome 47, février 1986

page $\mathrm{C} 1-353$

\title{
HIGH TEMPERATURE MECHANICAL PROPERTIES AND INTERGRANULAR STRUCTURE OF SIALONS
}

\author{
A. THOREL * ${ }^{*}$, J.Y. LAVAL ${ }^{*}$ and D. BROUSSAUD* \\ - Laboratoire des Microstructures, UA 450, CNRS-ESPCI, 10, Rue \\ Vauquelin, F-75231 Paris Cedex 05, France \\ *Centre des Matériaux, Ecole des Mines, B.P. 87, F-91003 Evry \\ Cedex, France
}

\begin{abstract}
Résumé - Deux types de sialons dont 1'un a subi un pressage isostatique à chaud (H.I.P.) ont été analysés en combinant différentes techniques de microscopie electronique analytique en transmission. On montre que le pressage isostatique à chaud homogénéise la granulométrie et également la microstructure intergranulaire. La méthodologie utilisée permet de relier cette microstructure aux propriétés mécaniques à haute température et en particulier de mettre en relief le rôle spécifique des interfaces.
\end{abstract}

Abstract - Two types of sialons which differ by the processing conditions (one has been submitted to hot isostatic pressing after sintering) were analyzed by simultaneous techniques in transmission electron microscopy. It was shown that both granulometry and intergranular microstructure are homorgeneized by hot isostatic pressing. The methodology used allows to relate the high temperature mechanical properties to the microstructural characteristics and to reveal the specific role of interfaces.

\section{INTRODUCTION}

The thermo-mechanical behaviour of sialon-type ceramics are strongly dependent on their intergranular microstructure which can be either glassy, crystalline or mixed according to the starting compositions and to the processing conditions. Materials with a crystalline boundary phase (CBP)may keep high strength up to $1200^{\circ} \mathrm{C}$. On the other hand materials which exhibit a vitreous boundary phase (VBP) will display a higher shock resistance. In this second case, it has been established that vitreous interfacial films. (VIF) lead to higher performances $/ 1 /$.

Recent works have suggested that it is possible to obtain a selected intergranular structure from a basic material by using only thermo-mechanical post-sintering heat treatments (HIP, oxidation, crystallization ...) $/ 2,3 /$. Consequently the improvement of a material for a specified application requires a complete knowledge of the influence of this microstructure on the mechanical properties. Due to the thinness of the intergranular layer (1-100 nm) the only available characterization technique is transmission electron microscopy.

The aim of this paper is primarily to propose a specific methodoly for characterizing vitreous and crystalline boundary phases (VBP, CBP) as well as vitreous interfacial filns (VIF) using a technique that avoids artefacts due to geometric effects, absorption contrast and ion thinning. Then, it should be emphasized that it is difficult to establish the relationship between macroscopic behaviour and intergranular structure since changes in flansdistribution and in density that occur

* A,B correspond to the trade designations N3, N32 
during pressing must also be taken into account. However, we try then to give experimental evidences upon the influence of the intergranular structure on some mechanical properties such as fracture strength and toughness.

\section{EXPERIMENTAL}

Two yttria-doped sialon type ceramics $(A)$ and $(B)$ from CERAVER have been investigated - (B) material is identical to (A) but has been submitted to a HIP treatment after sintering. The starting powder composition is given in table I.

Table I /4/ Starting powder composition

\begin{tabular}{|c|c|c|c|c|c|}
\hline \multirow{2}{*}{$\mathrm{w}^{\circ} \cdot \mathrm{Si}$} & $\mathrm{Al}$ & $\mathrm{Y}_{2} \mathrm{O}_{3}$ & $\mathrm{Fe}$ & $\mathrm{Ca}$ \\
\cline { 2 - 6 } & 80,35 & 5,6 & 14,05 & 0,35 & 0,6 \\
\hline
\end{tabular}

Nitridation and sintering lead for both materials to the stoechiometric formula for $\beta^{\prime}-$ sialon grains :

$$
\mathrm{Si}_{5,6} \mathrm{Al}_{\mathrm{O}, 4} \mathrm{O}_{\mathrm{O}, 4} \mathrm{~N}_{7,6} \quad / 4 /
$$

For microstructural investigation, two analytical TEM-STEM have been used : a JEOL $100 \mathrm{CX}(120 \mathrm{KV})$ equipped with an EDAX X-ray analyser and a Philips EM 430 ( $300 \mathrm{KV})$. Micro-analysis in STEM mode have been carried out using a $150 \AA$ diameter microprobe. Specimens have been prepared by ion-milling from a thickness of $\simeq 40 \mu \mathrm{m}$

\section{RESULTS}

Previous $\mathrm{X}$-ray analysis have shown that both materials display the hexagonal symmetry of $\beta^{\prime}$-sialon phase $/ 4 /$. The $\beta^{\prime}$-grains are embedded in an intérgranular phase which arises from the yttria sintering additive and the segregation of impurities. Mechanical behaviour of sialon (A) and (B) at room temperature are displayed in table II, in terms of average rupture strength $\sigma_{R}$, modulus of Weibull $\mathrm{m}$ and fracture toughness $\mathrm{K}_{\mathrm{IC}}$.

Table II : Characteristics of sialons

\begin{tabular}{|c|c|c|c|c|c|c|c|}
\hline Mat & Process & $\begin{array}{c}\rho \\
\mathrm{g} / \mathrm{cm}^{3}\end{array}$ & $\begin{array}{c}\sigma \mathrm{R} \\
\mathrm{MPa}\end{array}$ & $\mathrm{m}$ & $\begin{array}{c}\mathrm{K} \mathrm{IC} \\
\mathrm{MPa} \sqrt{\mathrm{m}}\end{array}$ & $\mathrm{H}(\mathrm{KPa})$ & $\mathrm{E}(\mathrm{GPa})$ \\
\hline (A) & as sintered & 3,2 & 530 & 12 & 4 & 15,3 & 275 \\
\hline (B) & $\begin{array}{c}\text { as sintered } \\
+ \text { HIP }\end{array}$ & 3,26 & 800 & 14 & 4,4 & 16,3 & 280 \\
\hline
\end{tabular}

Conventional TEM analysis (dark field, bright field, selected area diffraction) allows one to characterize extended thin areas of glass boundary phases (thinness $1000 \AA$, diameter $5000 \AA)$. Nevertheless, when the geometry is complex or the vitreous phase thick, the characteristic diffuse halo may be too weak. Then microdiffraction technique must be used or electron irradiation induced effects which lead to the formation of oxygen bubbles via Si-O bond radiolysis (Fig.1) /5/. Dark field imaging can lead to misinterpretation of grain boundary structures. From Fig. 2a which shows a dark field image of a triple junction with a diffracted intensity at the grain boundary, one could assume the presence of a vitreous interfacial film. However, high resolution imaging using $\{100\}$ planes (Fig. $2 b$ ) evidences that no vitreous film is present.

Using these procedures, one may compare the microstructure of each sialon. .

\section{Sialon A}

Fig. 3a shows a typical aspect of sialon (A) which is composed of $B$ ' grains with an average size of $1 \mathrm{um}$ and an heterogeneous intergranular phase. With the techniques described above and microanalysis, it has been shown that :

1) the intergranular phase is always glassy and mostly in fairly large pockets $(0.1$ to $1 \mu \mathrm{m}$ ) with the composition of a mixed aluminium and yttrium silicate (with $\mathrm{N}$, 
$\mathrm{Ca}$ and $\mathrm{Fe}$ as substituted elements) (Fig. 3).

2) the intergranular glassy phase is not continuous. All the $30 \beta^{\prime}$ boundaries studied are essentially free of glassy phases (Fig. 2 and $4 \mathrm{a}$ ).

3) the $\beta^{\prime}-\beta^{\prime}$ or $\beta^{\prime}-$ glass interfaces are often parallel to simple $\{100\}$ planes and contain reticular steps as shown in Fig. 4. The atomic planes corresponding to these steps could be either plane 1 or 2 in Fig. 5. Both planes contain nitrogen atoms only but plane 1 which is denser seems more probable.

\section{Sialon B}

The macroscopic aspect of (B) seems to be more homogeneous than (A) especially for the intergranular phase which is also glassy and which does not exhibit large pockets as in (A) (Fig. 6). Chemical composition of this glassy phase is quite similar to the one observed in (A). But the main difference brought by HIP is that most of the grain boundaries now have an interfacial vitreous film ( $110 \AA)$ (Fig. 7). However, it was not possible yet to decide whether this VIF is continuous or not.

DISCUSSION

As far as mechanical properties are concerned, sialon (B) exhibits a higher rupture strength than (A) $\left(\Delta \sigma_{\mathrm{R}}>300 \mathrm{MPa}\right)$, whereas both display a maximum in fracture toughness and a drop off in strength in the range $900-1050^{\circ} \mathrm{C}$. High temperature mechanical behaviour of (A) and (B) are similar with other commercial sialon (Fig. 8) which also show a drop off due to the presence of a glassy grain boundary phase. This is consistent with our previous results $/ 6 /$. A maximum in fracture toughness has already been observed in hot pressed silicon nitride /7/ and has been attributed to crack blunting mechanisms linked to the decreasing viscosity of the glassy phase with the temperature. A correlation between microstructure and increase in strength by HIP is not, however, readily established.

Several data on HIP materials have shown that fracture strength increases with the $\beta^{\prime}$ aspect ratio (length/width) /8/ which is accentuated with sintering additives $/ 9 /$. The fracture strength also increases with the density and decreases with grain size /10/. It has been suggested for $\mathrm{Si}_{3} \mathrm{~N}_{4}$ that an equiaxed to rod-shaped grain transformation occurring during HIP implies the presence of the $\alpha$ phase in the starting material, but this is not the case here. HIP processing for (B) material, which contains a glassy intergranular phase, does not change the flawsdistribution, ( $m$, modulus of Weibull goes up from 12 for (A) to 14 for (B)). This distribution seens to correspond to the pores population : densification occurs by an homothetic decrease in pore size principally near the glassy phase. It has been observed in hot isostatically pressed alumina-glass composites that the viscous glass flows from the grain boundaries to the macropores and might be conducive to pore filling and collapsing $/ 11 /$. The consequence is an increase in strength with a constant $\mathrm{m}$ value. Moreover the lack of vitreous film in sialon (A) means that the grains gather into clusters with crystallographic relationships leading to tough boundaries. The formation of these rigid clusters could contribute to the discrepancy in $\sigma$. The delay in temperature $\Delta T$ between high temperature fracture stress of $(A)$ and (B) may have several reasons involving glassy pockets in (A) - which lead to large flaws - or changes in glass viscosity. Since it has been established that viscosity was proportional to the $N$ : 0 ratio /12/ this could explain why the VIF which may correspond to an enhancement in nitrogen concentration, would be more viscous than the microstructure with large glassy pockets.

\section{CONCLUSION}

It has been evidenced that the intergranular microstructure can be changed by hot isostatic pressing, i.e. the microstructure with glassy pockets transforms to a vitreous intergranular film. In the case of a glassy intergranular microstructure, the pores distribution seems to control the room temperature fracture strength. At higher temperature the fracture mechanisms are more complex involving viscosity changes of the grain boundary phase or vitreous intergranular film and cristallographic relationships between $\beta^{\prime}$ - grains.

ACKNONLEDGMENT : This work was supported by CNRS (ATP $n^{\circ}$ 983011). Mrs N. PASQUALINI and Mr. B. GUEROULT are thanked for mechanical measurements and discussion 


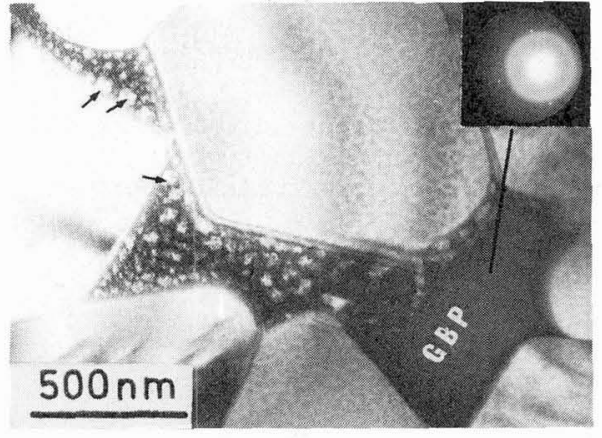

Fig. 1 : Sialon (A) :

Induced effects and microdiffraction on glassy intergranular phase (bright field, $100 \mathrm{KV}$ )

Fiq. 2 : Sialon (A)

a) Dark field imaging of triple junction with a grain boundary (arrowed), (100 KV)

b) High resolution imaging of the same grain boundary which does not exhibit a glassy film ( $\{100\}$ planes, bright field, $100 \mathrm{kV})$
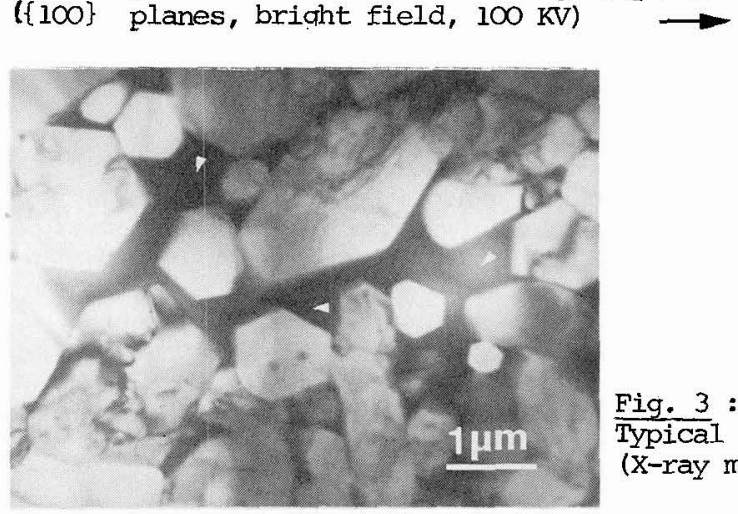

Fig. 3 : Sialon (A)

Typical structure with glassy pockets (X-ray micro-analysis, $100 \mathrm{KV}, 150 \mathrm{~A}$ microprobe)


Fig. 4 : Interfaces in sialon (A) parallel to $\{100\}$ planes and showing $\{100\}$ reticular steps (bright field, $300 \mathrm{kV}$ )

a) $\beta^{\prime}-\beta^{\prime}$ vitreous-film-free grain boundary

b) $B^{\prime}$ - glass interfaces 


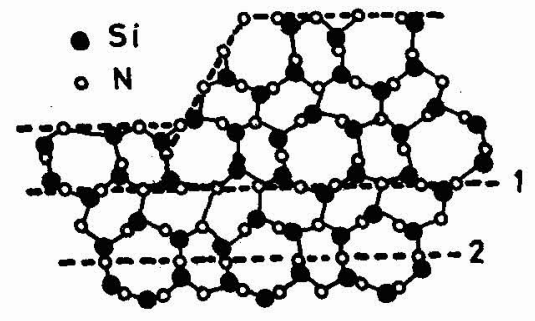

a.

Fig. 5 : $\beta^{\prime} \mathrm{Si}_{3} \mathrm{~N}_{4}$ projection in basal plane with two types of steps

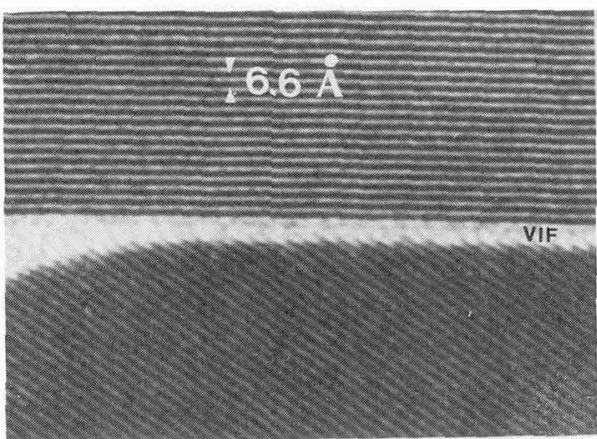

Fig. 7 : Sialon $\mathrm{B}$ : High resolution imaging of a vitreous interfacial film (VIF) (bright field, $300 \mathrm{KV}$ )

b

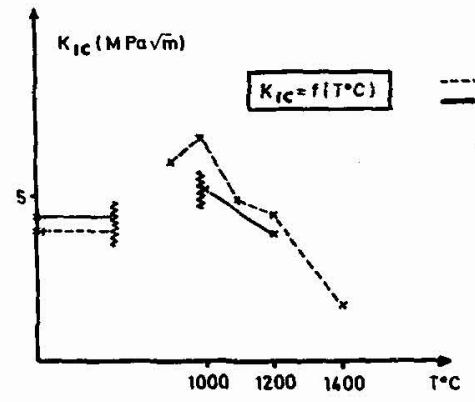

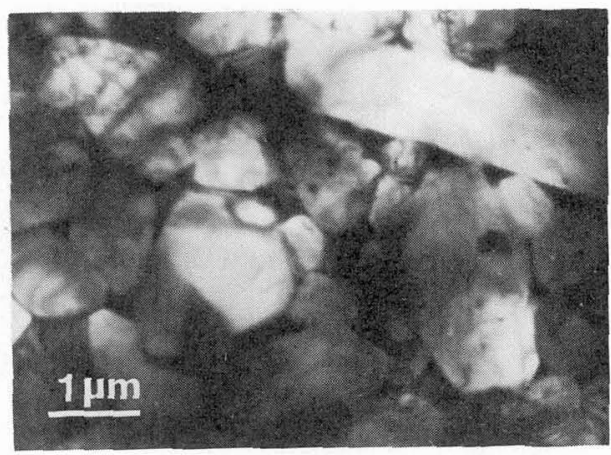

Fig. 6 : Typical structure of sialon B

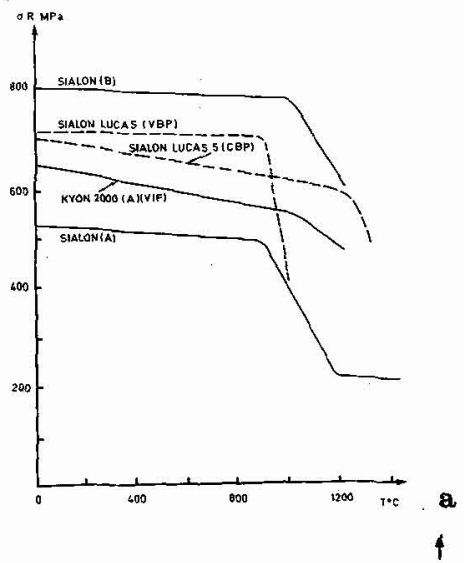

Fig. 8 : Mechanical properties of the studied sialons a) rupture strength $\sigma_{R}$

- b) fracture toughness $\mathrm{K}_{\mathrm{IC}}$

\section{RFFERENCES}

/1/ Laval J.Y., Amamra M.C., Broussaud D. et Mustel W., Rev. Chimie Miner. (1982) 19 690

12) Clarke D.R., J. Am. Ceram. Soc. (1983) 66 , 92

/3/ Clarke D.R., IANGE F.F, and Schnittorund G.D., J. Am. Ceram. Soc. 65 (1982) C51

14/ Chartier T., Thèse de Docteur-Ingénieur, ENSCI (1985)

15/ Laval J.Y., Westmacott K.H., Amamra M.C., J. Phys. 43 (1982) C9-123

/6/ Laval J.Y., Delamarre C, Amamra M.C., Broussaud D., J. Mat. Science 20, (1985) 381

7/ Knickerbocher S.H., Zangvil A. and Brown S.D., J. Am. Ceram. Soc., 67 (1984) 365

/8/ Heinrich J. and Böhmer M. J. Am. Ceram. Soc., 67 (1984) C75

19/ Heinrich J. and Böhmer M., Science of Ceramics, 11 (1981) 439

/10/ Watson G.K., Moore T.J., Milliard M.L., J. Am. Ceram. Soc., 67, (1984) C208

111/Kwon O.H. and Messing G.L., J. Am. Ceram. Soc., 67 (1984) C43

/12/ Hampshire S., Drew R.A.L., Jack K.H., J. Am. Ceram. Soc., 67 (1984) C46 